\title{
Efficacy and safety of sitagliptin as a third therapeutic agent in the treatment of type 2 diabetes mellitus
}

\author{
Fatemeh Hayati', Amjed Hazim², Teguh Haryo Sasongko', Gan Siew Hua', Wan Mohd Izani Wan Mohamed ${ }^{3}$, Juhaida Daud ${ }^{4}$, \\ Nik Soriani Yaacob² and Wan Mohamad Wan Bebakar ${ }^{3^{*}}$ \\ *Correspondence: wanmohd@usm.my

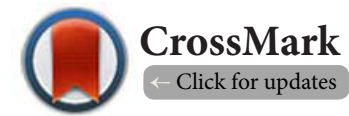 \\ ${ }^{1}$ Human Genome Center, School of Medical Science Universiti Sains Malaysia, 16150 Kubang Kerian, Kota Bharu, Kelantan, Malaysia. \\ 2Department of Chemical Pathology, School of Medical Science Universiti Sains Malaysia, 16150 Kubang Kerian, Kota Bharu, \\ Kelantan, Malaysia. \\ ${ }^{3}$ Department of Medicine, School of Medical Science Universiti Sains Malaysia, 16150 Kubang Kerian, Kota Bharu, Kelantan, Malaysia. \\ ${ }^{4}$ Family Medicine Clinic, School of Medical Science Universiti Sains Malaysia, 16150 Kubang Kerian, Kota Bharu, Kelantan, Malaysia.
}

\begin{abstract}
Background: Information on sitagliptin as a third line agent in combination with other antidiabetic agents is still lacking. This study evaluated the safety and efficacy of sitagliptin as an add-on therapyin type 2 diabetes mellitus (T2DM) patients with poorly controlled glucose control despite receiving an optimum dose ofmetforminand sulphonylurea.

Method: In a 24-week, non-randomized, open-labeled trial study, T2DM patients (n=93) who were on optimum dosage of metformin and sulphonylurea were additionally treated with $100 \mathrm{mg}$ sitagliptin daily. Primary efficacy end point was assessed by investigating the changes in hemoglobin A1C (HbA1c) and a secondary efficacy end point was assessed by fasting plasma glucose (FPG). Safety was assessed by recording of hypoglycemia, change in body mass index (BMI), blood pressure, lipid profiles high density lipoprotein (HDL), low density lipoprotein (LDL), total cholesterol (Tc) and triglycerides, serum aspartate aminotransferase (AST), alanine transaminase (ALT), alkaline phosphatase (ALP), urea, uric acid and creatinine levels.

$\underline{\text { Result: }}$ The mean HbA1c was reduced by $0.41 \%(P<0.007)$, and overall, $18.27 \%$ of patients achieved an HbA1c goal of $<7 \%$. After 6 months. ALP was reduced by $5.23(P=0.035)$ and uric acid was increased by $16.20 \mu \mathrm{mol} / \mathrm{l}(P=0.048)$ respectively. There was no significant change in LDL, Tc, triglycerides, FPG, BMI, blood pressure, urea, AST and ALT. Hypoglycemia was observed only in a small percentage (2.65\%) of patients. Although uric acid levels were slightly increased in this study, they were still within the normal range.

Conclusion: Sitagliptin is effective and safe to be used in combination with metformin and sulphonylurea therapies.
\end{abstract}

Keywords: Diabetes, dipeptidyl peptidase 4 inhibitors, sitagliptin, HbA 1c

\section{Introduction}

Improvement in glucose control is the most important therapeutic approach in primary prevention of diabetic complications. To date, several oral anti-hyperglycemic drugs are available to induce glucose level to near normalcy. Evidence from the literature has demonstrated that a high percentage $(60 \%)$ of patients do not achieve glycemic targets due to the progressive nature of type 2 diabetes (T2DM) making combination therapy for optimal glycemic control a necessity [1].
Ensuring optimal efficacy of the drug in mono- or combination therapies during clinical trials is of paramount importance to ensure the safety of patients while giving minimal adverse effects. There are different classes of anti-diabetic drugs, the selection of which is dependent on the type of diabetes, patients and drug characteristics [2]. Thiazolidinedione, glinides, sulphonylurea, pramlinitide, metformin and glucagon-like peptide-1 agonists (GLP-1) are beneficial in lowering hemoglobin A1C (HbA1c) but are not without adverse effects [3]. Dipeptidyl peptidase 4 
inhibitors (DPP-4 inhibitors) also play a vital role in the treatment of diabetes and have relatively limited adverse effects.

Sitagliptin is an orally active, potent and highly selective DPP-4 inhibitors usually prescribed in a single daily dose. Sitagliptin is approved in many countries for the treatment of patients with T2DM. The safety and efficacy of sitagliptin monotherapy in treating T2DM has previously been well-established [4]. Additionally, the efficacy and safety of sitagliptin have also been established among T2DM patients who do not have adequate glycemic controls with metformin monotherapy [5-17]. However, information on the efficacy and safety of sitagliptin when prescribed as a third line agent in addition to other oral anti hyperglycemic drugs isstill lacking. This trial was conducted to determine the benefits of sitagliptin when used in combination with metformin and sulphonylurea by addressing its efficacy and safety.

\section{Materials and methods Patients}

Patients were diagnosed as having T2DM based on the 1998 revised diagnostic criteria established by the World Health Organization Expert Committee (WHO). All were adult patients ageing 18 and above with no history of myocardial infarction or malignancy observed within six months prior tothe study. Subjects with $\mathrm{HbA} 1 \mathrm{c}$ levels between $7 \%$ and $11.5 \%$ as well as serum creatinine levels ofless than $130 \mu \mathrm{mol} / \mathrm{l}$ were eligible for the trial. Only patients who have not been treated with any type of DPP-4 inhibitor before the trial were recruited. Patients who had a prior history of impaired hepatic function were excluded.

\section{Study design}

A prospective, non-randomized, single arm, intervention study design was used. A total of 93 patients were assigned to receive sitagliptin ( $100 \mathrm{mg}$ daily) in addition to their previous medications (metformin and sulphonylurea). Data collection was conducted before andafter 24 weeks of sitagliptin therapy. All patients were enrolled following signed written informed consents. The protocol as well as patient consent forms were approved by the Human Research Ethics Committee, Universiti Sains Malaysiaper reference USMKK PPP JEPeM [230.3] [13], prior to study commencement. The study was conducted in accordance with Good Clinical Practice and complies with the Declaration of Helsinki.

\section{Study end points}

The primary efficacy end point of this trial was the change in $\mathrm{HbA} 1 \mathrm{c}$ values from the baseline. The secondary efficacy end points were changes in fasting plasma glucose (FPG), when compared to baseline.

\section{Safety end points}

The data were collected from history, physical and laboratory examination throughout the 24 weeks treatment period.
Laboratory investigations included blood chemistry for urea, uric acid, creatinine, aspartate aminotransferase (AST), alanine transaminase (ALT), alkaline phosphatase (ALP) and lipid profiles. Anyclinical adverse events were assessed by investigators for their possible relationships with the study drug. The adverse events of interest included hypoglycemia and gastrointestinal effects such as abdominal pain or discomfort, nausea, vomiting and diarrhea. Mild hypoglycemia is defined as that which is recognized and treated by the patients themselveswhile severe hypoglycemia is defined as that which patients are unable to self-treat due to impairment of cognitive function. All laboratory measurements were conducted at the Universiti Sains Malaysia (Chemical Pathology and Endocrinology laboratories). The $\mathrm{HbA} 1 \mathrm{c}$ levels were analyzed using high performance liquid chromatography (Bio-Rad D-10 analyzer, USA) method. FPG, lipid profiles, AST, ALP, ALT, uric acid were determined using enzymatic methods whileurea and serum creatinine were measured using ultraviolet and kinetic colorimetric assay methods respectively.

\section{Statistical analysis}

All statistical analyses were conducted using SPSS (Chicago, IL, USA) software version 19.0 for Microsoft Windows ${ }^{\circledR}$. The patients' clinical characteristics were expressed as mean \pm SD. Pre-and post-trial measurements were statistically analyzed usingpaired sample t-tests. Changes were considered clinically significantwhen $\mathrm{P}<0.05$.

\section{Results}

\section{Patient demographics, baseline disease characteristics and disposition}

A total of 800 patients were screened in this study (Figure 1). From this number, 130 fulfilled the inclusion and exclusion criteria out of which 113 were successfully enrolled. During the study, 20 subjects dropped out due to gastrointestinal side effects [2], hypoglycemia [3], headache and dizziness [2], difficulty in passing urine [1], hyponatremia [1] and chest pain [1] while10 patients failed to followup. The baseline characteristics

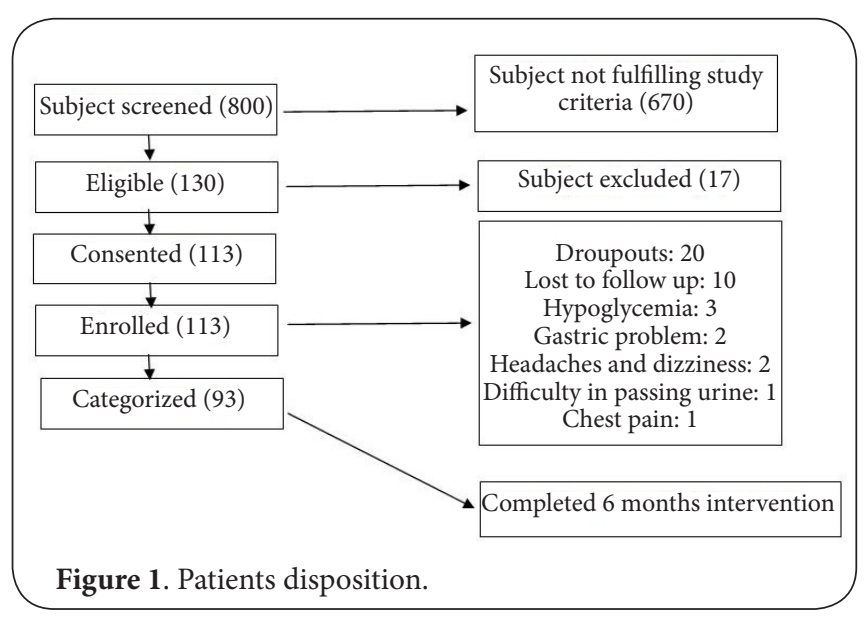


of the subjects are summarized in Table 1. The majority of subjects received gliclazideas sulphonylurea before and during the study. The dose of metformin and sulphonylurea were maintained throughout the study.

Table 1. Baseline characteristics of all subjects.

\begin{tabular}{ll}
\hline Characteristics & Subjects \\
\hline Male:Female & $44: 49$ \\
Age $(\mathrm{yr})$ & $55.55 \pm 8.789$ \\
Duration of T2DM $(\mathrm{yr})$ & $7.52 \pm 4.524$ \\
SBP $(\mathrm{mmHg})$ & $135.31 \pm 17.87$ \\
DBP $(\mathrm{mmHg})$ & $81.49 \pm 9.466$ \\
BMI $\left(\mathrm{kg} / \mathrm{m}^{2}\right)$ & $29.023 \pm 5.117$ \\
FPG $(\mathrm{mmol} / \mathrm{l})$ & $8.872 \pm 3.294$ \\
HbA1c $(\%)$ & $8.897 \pm 1.30$ \\
\hline
\end{tabular}

Data are expressed as means \pm SD unless otherwise stated. T2DM: Type 2diabetes mellitus; SBP: Systolic blood pressure; DBP: Diastolic blood pressure; BMI: Body mass index; FPG: Fasting plasma glucose; T2DM: Type 2diabetes mellitus; SBP: Systolic blood pressure; DBP: Diastolic blood pressure; BMI: Body mass index; FPG: Fasting plasma glucose

\section{Efficacy}

The patients' mean $\mathrm{HbA} 1 \mathrm{c}$ levels were significantly decreased following 6 months of treatment with sitagliptin $0.41 \%(P<0.007)$ (Table 2). However, the change in $\mathrm{HbA} 1 \mathrm{c}$ levels varied substantially from one patient to another with patients having higher levels of baseline HbA1c (>9\%) had greater mean reductions in $\mathrm{HbA1c}$ (Figure 2). Eightenpercent of patients had a reduction of $\mathrm{HbA} 1 \mathrm{c}$ to below $7 \%$. At the end of the trial. There was no significant difference between the mean FPG after 6 months when compared to baseline $(p=0.283)$.

\section{Body mass index (BMI) and blood pressure (BP)}

There was a $0.07 \mathrm{~kg} / \mathrm{m}^{2}$ decrease in the mean BMl of all subjects

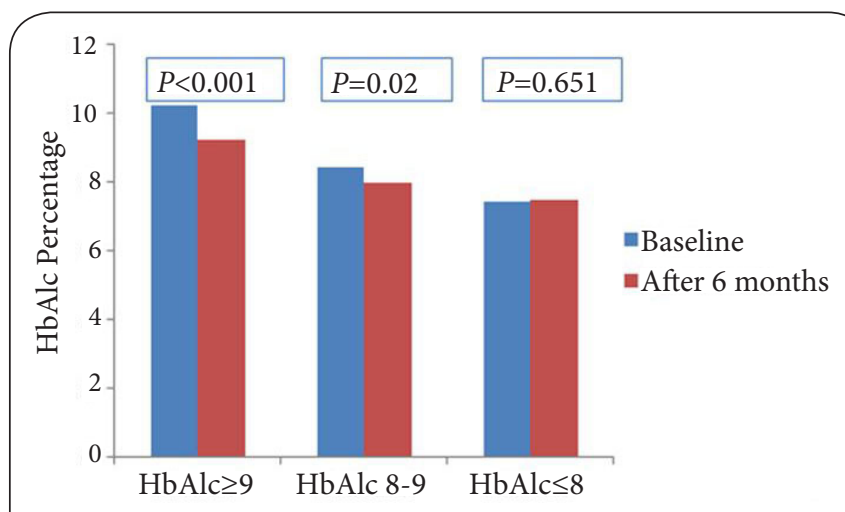

Figure 2. HbAlc reduction after 6 months of treatment base on baseline HbAlc.

at 24 weeks when compared to baseline $(P=0.475)$. However, the difference is not statistically significant (Table 2). There was also no significant difference between the systolic blood pressure (SBP) $(P=0.2)$ and diastolic blood pressure (DBP) $(P=0.907)$ at 24 weeks when compared to baseline.

\section{Lipid profiles}

After 6 months of sitagliptin therapy, significant changes were observed in mean HDL. No significant change were observed in LDL, triglyceride and total cholesterol levels (Table 2).

\section{Safety}

\section{Hypoglycemia}

Treatment with sitagliptin was generally well-tolerated over the 6 months treatment period. Clinical adverse events were reported in $8.84 \%$ of subjects leading to discontinuation of therapy. Mild hypoglycemia, reported in $2.65 \%$ of cases, was the most frequently reported adverse event followed by gastric problems $(1.76 \%)$, headache and dizziness $(1.76 \%)$, hyponatremia and chest pain $(0.88 \%)$.

\section{Biochemical parameters}

There was no significance difference between ALT, AST, serum

Table 2. Summary of efficacy parameters following 6 months co-therapies with sitagliptin.

\begin{tabular}{lllcl}
\hline Parameters & Baseline & 6 months & T statistic (df) & P value \\
\hline Weight $(\mathrm{kg})$ & $73.56 \pm 16.474$ & $73.39 \pm 16.372$ & $0.595(92)$ & 0.553 \\
BMI $\left(\mathrm{kg} / \mathrm{m}^{2}\right)$ & $29.018 \pm 5.171$ & $28.941 \pm 5.109$ & $0.718(92)$ & 0.475 \\
Systolic BP $(\mathrm{mmHg})$ & $135.31 \pm 17.876$ & $138.25 \pm 21.280$ & $-1.291(92)$ & 0.2 \\
Diastolic BP $(\mathrm{mmHg})$ & $81.49 \pm 9.466$ & $81.30 \pm 13.160$ & $0.117(92)$ & 0.907 \\
HDL $(\mathrm{mmol} / \mathrm{l})$ & $1.234 \pm 0.255$ & $1.176 \pm 0.248$ & $3.493(92)$ & 0.001 \\
LDL $(\mathrm{mmol} / \mathrm{l})$ & $2.848 \pm 0.959$ & $2.959 \pm 1.117$ & $-1.006(91)$ & 0.317 \\
Triglyceride $(\mathrm{mmol} / \mathrm{l})$ & $1.758 \pm 1.166$ & $1.904 \pm 1.521$ & $-9.860(92)$ & 0.326 \\
TC (mmol/l) & $4.856 \pm 1.213$ & $4.931 \pm 1.332$ & $-0.597(92)$ & 0.552 \\
FPG $(\mathrm{mmol} / \mathrm{l})$ & $8.872 \pm 3.294$ & $9.327 \pm 3.516$ & $-1.080(92)$ & 0.283 \\
HbA1C $(\%)$ & $8.897 \pm 1.363$ & $8.480 \pm 1.613$ & $2.740(92)$ & 0.007 \\
\hline
\end{tabular}

$\mathrm{P}$ value calculated using paired sample t test 
creatinine and urea levels following 6 months of therapy with sitagliptin when compared to baseline (Table 3). Uric acidlevels however, showed a slightly significant increase $(P=0.048)$ which was still within normal range. The level of ALP was significantly decreased $(P=0.035)$ following sitagliptin therapy.

Table 3. Summary of biochemical parameters.

\begin{tabular}{lllll}
\hline Parameters & Baseline & $\mathbf{6 ~ m o n t h s}$ & $\begin{array}{l}\text { T statistic } \\
(\mathbf{d f})\end{array}$ & P value \\
\hline $\begin{array}{l}\text { Creatinine } \\
(\mu \mathrm{mol} / \mathrm{l})\end{array}$ & $94.080 \pm 18.189$ & $94.090 \pm 21.9$ & $-0.007(92)$ & 0.994 \\
$\begin{array}{l}\text { Urea } \\
(\mathrm{mg} / \mathrm{dl})\end{array}$ & $5.382 \pm 1.562$ & $5.175 \pm 1.983$ & $1.404(92)$ & 0.164 \\
Uric acid & $342.60 \pm 96.810$ & $358.59 \pm 117.759$ & $-2.005(92)$ & 0.048 \\
AST $(\mathrm{u} / \mathrm{l})$ & $29.90 \pm 13.539$ & $30.88 \pm 13.187$ & $-0.789(92)$ & 0.432 \\
ALT $(\mathrm{u} / \mathrm{l})$ & $43.74 \pm 26.837$ & $43.30 \pm 23.909$ & $0.272(92)$ & 0.787 \\
ALP $(\mathrm{u} / \mathrm{l})$ & $93.12 \pm 28.658$ & $88.69 \pm 27.901$ & $2.140(92)$ & 0.035 \\
\hline
\end{tabular}

\section{Discussion}

This study was carried out to determine the efficacy and safety of $100 \mathrm{mg}$ sitagliptin, taken once daily as an add-on therapy, in patients with T2DM whose glucose levels were inadequately controlled despite being on optimum doses of metformin in combination with sulphonylurea were investigated over 6 months of treatment. The study revealed a reduction in mean $\mathrm{HbA} 1 \mathrm{C}$ by $0.41 \%$ from baseline. Overall, $18.27 \%$ patients achieved the American Diabetes Association recommended $\mathrm{HbA} 1 \mathrm{c}$ goal of $<7.0 \%$ [18] after 6 months of therapy. In previous multinational clinical trial of add sitagliptin in combination use with metformin and sulphonylurea [19], patients $(n=102)$ with poorly controlled T2DM on glimepiride and metformin therapy received the addition of $100 \mathrm{mg}$ sitagliptin, once daily for 24 weeks. The -addition of sitagliptin reduced $\mathrm{HbA} 1 \mathrm{C}$ by $0.59 \%$ from baseline. The higher $\mathrm{HbA} 1 \mathrm{c}$ reduction in this study could be due to the higher mean baseline of $\mathrm{HbA} 1 \mathrm{c}$ and races different.

In another report [20], eighty-two subjects were sequentially recruited for a 52-week, prospective, single arm study. Sitagliptin was added to low dosage sulphonylurea (glimepride or gliclazide) with or without metformin for 52 weeks. The change in $\mathrm{HbA} 1 \mathrm{c}$ after 52 -week treatment was $-0.80 \%$ (95\% $\mathrm{Cl} 0.90$ to 0.68$)(p<0.001)$. Higher reduction in $\mathrm{HbA1c}$ compare to current study could be due to longer duration of study. In current study FPG did not decrease after 6 month of sitagliptin therapy. The fact that DPP-4 inhibitors reduce post prandial blood sugar more effectively than FPG.

DPP-4 inhibitors are also known as body weight-neutral [21]. We observed that there was no significant change in BMI following 6 months sitagliptin therapy $(P=0.475)$. This result was consistant with previous study [20].

The HDL has decrease significantly in this study from 1.234 to $1.76 \mathrm{mmol} / \mathrm{L}(P=0.001)$. We conclude that the decrease of
HDL in this study could be due to the subjects diet which reflect by increasing in TG level.

Sitagliptin is known as a safe drug for both mono and combination therapies. Small percentage (2.65\%) of our patients experienced minor hypoglycemia. Among Japanese patients, the incidence of hypoglycemia was reported to be higher $4.28 \%$ ( 3 of 70 ) in 24 weeks when sitagliptin was added to low dosages of sulphonylurea or sulphonylurea and metformin [20].

ALP was decreased in the present study after 24 weeks of sitagliptin therapy $(P=0.035)$. It has been suggested that activation of incretin by sitagliptincan affect the levels of ALP [22]. In current study, we observed only a slight increase in uric acideven though the mean level was still within the normal range.

\section{Conclusion}

This study showed that treatment with $100 \mathrm{mg}$ sitagliptin, taken once daily in addition to metformin and sulphonylurea, led to clinically meaningful reductions in $\mathrm{HbA} 1 \mathrm{c}$. Overall, treatment with sitagliptin was well tolerated with low incidence of minor hypoglycemia.

\section{Competing interests}

The authors declare that they have no competing interests.

\section{Authors' contributions}

\begin{tabular}{|l|c|c|c|c|c|c|c|c|}
\hline Authors' contributions & FH & AH & TS & GS & WWM & JD & NY & WWB \\
\hline Research concept and design & $\checkmark$ & $\checkmark$ & $\checkmark$ & $\checkmark$ & $\checkmark$ & -- & $\checkmark$ & $\checkmark$ \\
\hline Collection and/or assembly of data & $\checkmark$ & $\checkmark$ & -- & -- & $\checkmark$ & $\checkmark$ & -- & $\checkmark$ \\
\hline Data analysis and interpretation & $\checkmark$ & -- & $\checkmark$ & $\checkmark$ & $\checkmark$ & -- & -- & $\checkmark$ \\
\hline Writing the article & $\checkmark$ & -- & -- & -- & -- & -- & -- & -- \\
\hline Critical revision of the article & -- & -- & $\checkmark$ & $\checkmark$ & $\checkmark$ & -- & $\checkmark$ & $\checkmark$ \\
\hline Final approval of article & -- & -- & -- & -- & -- & -- & -- & $\checkmark$ \\
\hline Statistical analysis & $\checkmark$ & -- & -- & -- & -- & -- & -- & -- \\
\hline
\end{tabular}

Acknowledgement and funding

The authors would like to thank the patients, staff of clinical trial unit, diabetic center and outpatient clinic of Hospital University Sains Malaysia. This study was supported by USM Research University grant 1001/PPSP/812094.

\section{Publication history}

Editor: Ippei Kanazawa, Shimane University Faculty of Medicine, Japan.

EIC: Geoffrey Burnstock, University College London, UK.

Received: 11-Oct-2014 Final Revised: 30-Nov-2014

Accepted: 08-Dec-2014 Published: 15-Dec-2014

\section{References}

1. Saydah SH, Fradkin J and Cowie CC. Poor control of risk factors for vascular disease among adults with previously diagnosed diabetes. JAMA. 2004; 291:335-42. | Article | PubMed

2. Mane PB, Antre RV and Oswal RJ. Antidiabetic drugs: An overview. International journal of pharmaceutical and chemical science. 2012 1:301-306.

3. Fass $A D$ and Gershman JA. Efficacy and safety of dipeptidyl peptidase-4 inhibitors in combination with metformin. Adv Ther. 2013; 30:337-53. | Article I PubMed 
4. Iwamoto Y, Tajima N, Kadowaki T, Nonaka K, Taniguchi T, Nishii M, Arjona Ferreira JC and Amatruda JM. Efficacy and safety of sitagliptin monotherapy compared with voglibose in Japanese patients with type 2 diabetes: a randomized, double-blind trial. Diabetes Obes Metab. 2010; 12:613-22. | Article | PubMed

5. Goldstein BJ, Feinglos MN, Lunceford JK, Johnson J and Williams-Herman DE. Effect of initial combination therapy with sitagliptin, a dipeptidy peptidase-4 inhibitor, and metformin on glycemic control in patients with type 2 diabetes. Diabetes Care. 2007; 30:1979-87. | Article | PubMed

6. Charbonnel B, Karasik A, Liu J, Wu M and Meininger G. Efficacy and safety of the dipeptidyl peptidase-4 inhibitor sitagliptin added to ongoing metformin therapy in patients with type $\mathbf{2}$ diabetes inadequately controlled with metformin alone. Diabetes Care. 2006; 29:2638-43. | Article | PubMed

7. Reasner C, Olansky L, Seck TL, Williams-Herman DE, Chen M, Terranella $L$, Johnson-Levonas AO, Kaufman KD and Goldstein BJ. The effect of initial therapywith the fixed-dose combination of sitagliptin and metformincomparedwithmetforminmonotherapy in patients with type 2 diabetesmellitus. DiabetesObesMetab. 2011; 13:644-52.

8. Williams-Herman D, Johnson J, Teng R, Luo E, Davies MJ, Kaufman KD, Goldstein BJ and Amatruda JM. Efficacy and safety of initial combination therapy with sitagliptin and metformin in patients with type 2 diabetes: a 54-week study. Curr Med Res Opin. 2009; 25:569-83. | Article | PubMed

9. Williams-Herman D, Johnson J, Teng R, Golm G, Kaufman KD, Goldstein $\mathrm{BJ}$ and Amatruda JM. Efficacy and safety of sitagliptin and metformin as initial combination therapy and as monotherapy over 2 years in patients with type 2 diabetes. Diabetes Obes Metab. 2010; 12:442-51. I Article I PubMed

10. Nauck MA, Meininger G, Sheng D, Terranella L and Stein PP. Efficacy and safety of the dipeptidyl peptidase-4 inhibitor, sitagliptin, compared with the sulfonylurea, glipizide, in patients with type $\mathbf{2}$ diabetes inadequately controlled on metformin alone: a randomized, doubleblind, non-inferiority trial. Diabetes Obes Metab. 2007; 9:194-205. | Article I PubMed

11. Bergenstal RM, Wysham C, Macconell L, Malloy J, Walsh B, Yan P, Wilhelm K, Malone $J$ and Porter LE. Efficacy and safety of exenatide once weekly versus sitagliptin or pioglitazone as an adjunct to metformin for treatment of type 2 diabetes (DURATION-2): a randomised trial. Lancet. 2010; 376:431-9. | Article | PubMed

12. Arechavaleta R, Seck T, Chen Y, Krobot KJ, O'Neill EA, Duran L, Kaufman KD, Williams-Herman D and Goldstein BJ. Efficacy and safety of treatment with sitagliptin or glimepiride in patients with type 2 diabetes inadequately controlled on metformin monotherapy: a randomized, double-blind, non-inferiority trial. Diabetes Obes Metab. 2011; 13:160-8. I Article I PubMed

13. Pratley RE, Nauck M, Bailey T, Montanya E, Cuddihy R, Filetti S, Thomsen $A B$, Sondergaard RE and Davies $M$. Liraglutide versus sitagliptin for patients with type 2 diabetes who did not have adequate glycaemic control with metformin: a 26-week, randomised, parallel-group, openlabel trial. Lancet. 2010; 375:1447-56. | Article | PubMed

14. Rigby SP, Handelsman Y, Lai YL, Abby SL, Tao B and Jones MR. Effects of colesevelam, rosiglitazone, or sitagliptin on glycemic control and lipid profile in patients with type 2 diabetes mellitus inadequately controlled by metformin monotherapy. Endocr Pract. 2010; 16:53-63. | Article | PubMed

15. Raz I, Chen Y, Wu M, Hussain S, Kaufman KD, Amatruda JM, Langdon RB, Stein PP and Alba M. Efficacy and safety of sitagliptin added to ongoing metformin therapy in patients with type 2 diabetes. Curr Med Res Opin. 2008; 24:537-50. | Article | PubMed

16. Kadowaki T, Tajima N, Odawara M, Nishii M, Taniguchi T and Ferreira JC. Addition of sitagliptin to ongoing metformin monotherapy improves glycemic control in Japanese patients with type $\mathbf{2}$ diabetes over $\mathbf{5 2}$ weeks. J Diabetes Investig. 2013; 4:174-81. | Article | PubMed Abstract | PubMed Full Text

17. Brazg R, Xu L, Dalla Man C, Cobelli C, Thomas K and Stein PP. Effect of adding sitagliptin, a dipeptidyl peptidase-4 inhibitor, to metformin on 24-h glycaemic control and beta-cell function in patients with type 2 diabetes. Diabetes Obes Metab. 2007; 9:186-93. I Article I PubMed

18. Standards of medical care in diabetes--2010. Diabetes Care. 2010; 33 Suppl 1:S11-61. | $\underline{\text { Article | PubMed Abstract | PubMed Full Text }}$

19. Hermansen K, Kipnes M, Luo E, Fanurik D, Khatami H and Stein P. Efficacy and safety of the dipeptidyl peptidase-4 inhibitor, sitagliptin, in patients with type 2 diabetes mellitus inadequately controlled on glimepiride alone or on glimepiride and metformin. Diabetes Obes Metab. 2007; 9:733-45. | Article | PubMed

20. Harashima SI, Ogura M, Tanaka D, Fukushima T, Wang Y, Koizumi T, Aono M, Murata Y, Seike M and Inagaki N. Sitagliptin add-on to low dosage sulphonylureas: efficacy and safety of combination therapy on glycaemic control and insulin secretion capacity in type 2 diabetes. Int $J$ Clin Pract. 2012; 66:465-76. | Article | PubMed

21. Gadsby R. Efficacy and Safety of Sitagliptin in the Treatmentof Type 2 Diabetes. Clinical Medicine.Therapeutics. 2009; 1:53-62.

22. Kubota A, Maeda H, Kanamori A, Matoba K, Jin Y, Minagawa F, Obana M, lemitsu K, Ito S, Amemiya $\mathrm{H}$ and Kaneshiro $\mathrm{M}$ et al. Pleiotropic effects of sitagliptin in the treatment of type 2 diabetes mellitus patients. J Clin Med Res. 2012; 4:309-13 1. | Article | PubMed Abstract | PubMed Full $\underline{\text { Text }}$

\section{Citation:}

Hayati F, Hazim A, Sasongko TH, Siew Hua G, Wan Mohamed WMI, Daud J, Yaacob NS and Wan Bebakar WM. Efficacy and safety of sitagliptin as a third therapeutic agent in the treatment of type 2 diabetes mellitus. J Diab Res Clin Met. 2014; 3:10. http://dx.doi.org/10.7243/2050-0866-3-10 